\title{
SMOKE-INDUCED GERMINATION IN PHACELIA STRICTAFLORA
}

\author{
Stanley A. Rice \\ Department of Biological Sciences \\ Southeastern Oklahoma State University \\ Durant, OK 74701-0609 \\ srice@se.edu
}

\author{
Sonya L. Ross \\ Department of Biological Sciences \\ Southeastern Oklahoma State University \\ Durant, OK 74701-0609 \\ sross76@student.se.edu
}

\section{Key words: butenolides, cross-timbers, fire, karrikens, regeneration}

\begin{abstract}
Seedlings of Phacelia strictiflora A.L. de Jussieu (Hydrophyllaceae) germinate profusely after major fires in the Cross Timbers forest of Oklahoma and rarely at other times and places. Seed germination was greatly enhanced under laboratory conditions by exposure to a water suspension of smoke chemicals. This is the first report of smoke enhancement of germination in a native Oklahoma plant species. Many plant species grow abundantly after disturbances including fires, but smoke enhancement of germination allows $P$. strictiflora to grow abundantly after fires and only rarely after other kinds of disturbance.
\end{abstract}

\section{INTRODUCTION}

Seeds of some plant species rarely germinate except after fires. These species grow in ecological communities that depend upon a fire cycle for regeneration. Examples include the chaparral (Keeley and Fotheringham 1998a; Keeley et al. 2012), the shrublands of Western Australia (Dixon et al. 1995; Thomas et al. 2007; Turner et al. 2009), and the South African fynbos (DeLange and Boucher 1990). Germination after fire may confer a great advantage on seedlings because the adult plants often form a dense cover against which the seedlings would be unable to successfully compete for light, water, and nutrients. Post-fire germination also allows seedlings to benefit from a flush of mineral nutrients provided by the ashes. Moreover, in firecycle communities, seeds may require exposure to one or more chemical components of smoke in order to germinate. In some cases, these chemicals may be oxidizing gases such as $\mathrm{NO}_{2}$ (Keeley and Fotheringham 1998b), while in other cases they may be a group of butenolides known as karrikins, which are growth regulators produced by the combustion of cellulose (Flematti et al. 2004; Chiwocha et al. 2009; Dixon et al. 2009).

In many cases, profuse germination after fires may result mainly from the sudden and greater abundance of light, water, and nutrients at the ground level, rather than from exposure to smoke chemicals. Many forms of disturbance other than fire also provide flushes of these resources. In this paper, we report that seed germination of Phacelia strictiflora A. L. de Jussieu (Hydrophyllaceae) is very strongly enhanced by smoke and rarely occurs without smoke stimulation. We also present evidence that post-fire germination of $P$. strictiflora seeds is not simply due to availability of a flush of resources or to stratification. This is the first report of 
smoke enhancement of germination in a native Oklahoma plant species.

Phacelia strictiflora is a native Oklahoma plant species that is a close relative of the chaparral P. grandiflora, in which smoke strongly enhances germination (Keeley and Fotheringam 1998a). P. strictiflora grows in poor soils in the south central United States. In Oklahoma, P. strictiflora is normally a rare spring annual in the Cross Timbers forest, which is noted for its poor soils. However, after major summer fires, $P$. strictiflora may grow and bloom profusely, forming nearly a monoculture in some areas, in the following spring (Figures 1, 2). The strong association between fire and germination led us to hypothesize that smoke chemicals greatly enhance the germination of $P$. strictiflora seeds.

\section{MATERIALS AND METHODS}

We collected seeds from mature, dry Phacelia strictiflora plants in a postfire area of the Blue River Wildlife Conservation Area maintained by the Oklahoma Department of Wildlife Conservation, near the junction of State Highway 7 and the Blue River in Bryan County ( $\left.34^{\circ} 21.50^{\prime} \mathrm{N}, 96^{\circ} 35.41^{\prime} \mathrm{W}\right)$. A wildfire destroyed most of the adult trees in 2011. We collected seeds of mature, senescent plants in May 2012 from ten different $25 \mathrm{~m}^{2}$ areas within the burned forest. We stored the dry seeds in plastic bags in the laboratory, at first at room temperature and later in a refrigerator, but we did not moisten the seeds except in the stratification treatment (see below). We used a dissecting microscope to carefully select healthy seeds (plump and free of discoloration) to use in the following experiments.

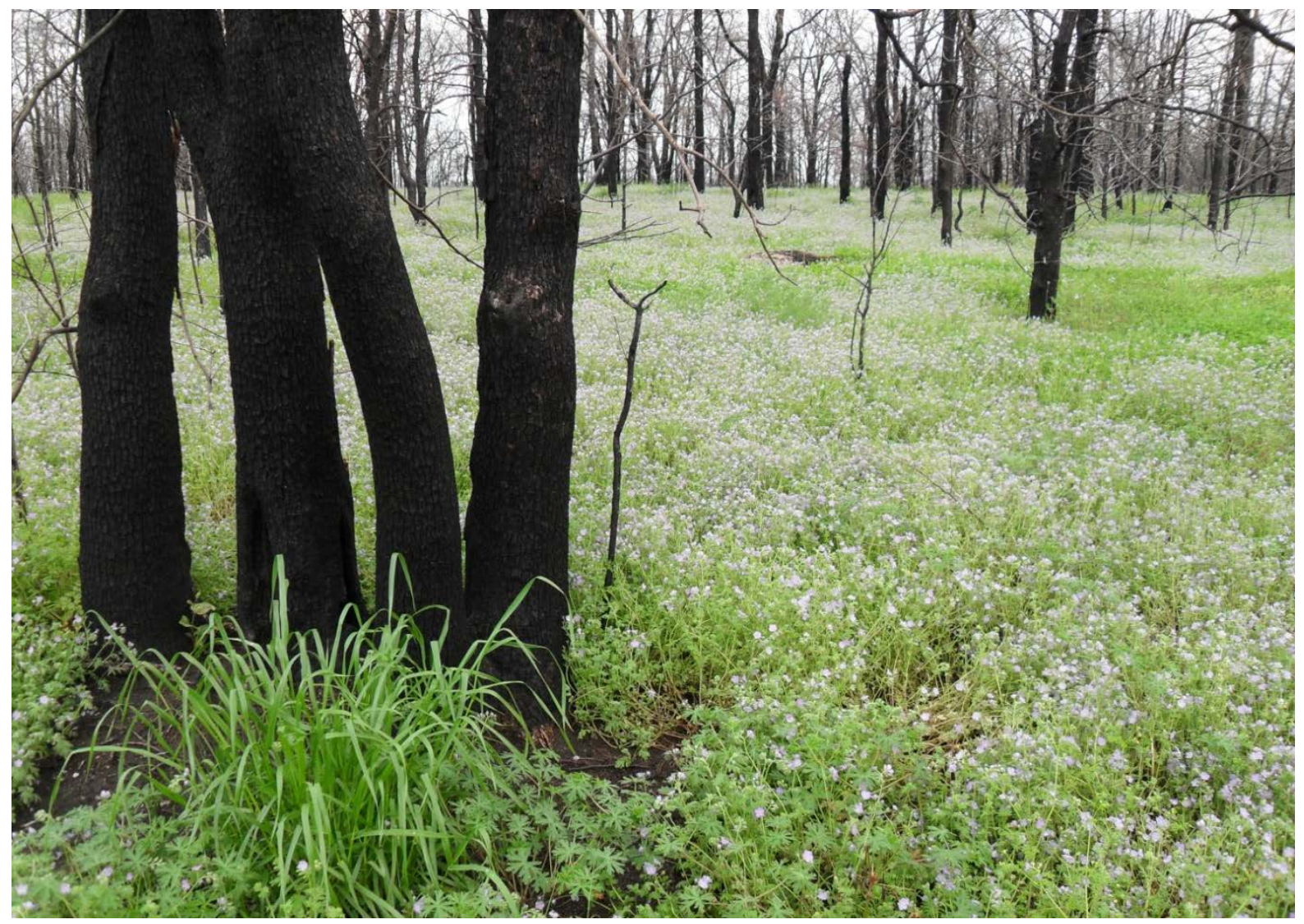

Figure 1 Phacelia strictiflora at the Blue River Wildlife Conservation Area the April following the 2011 fire. 


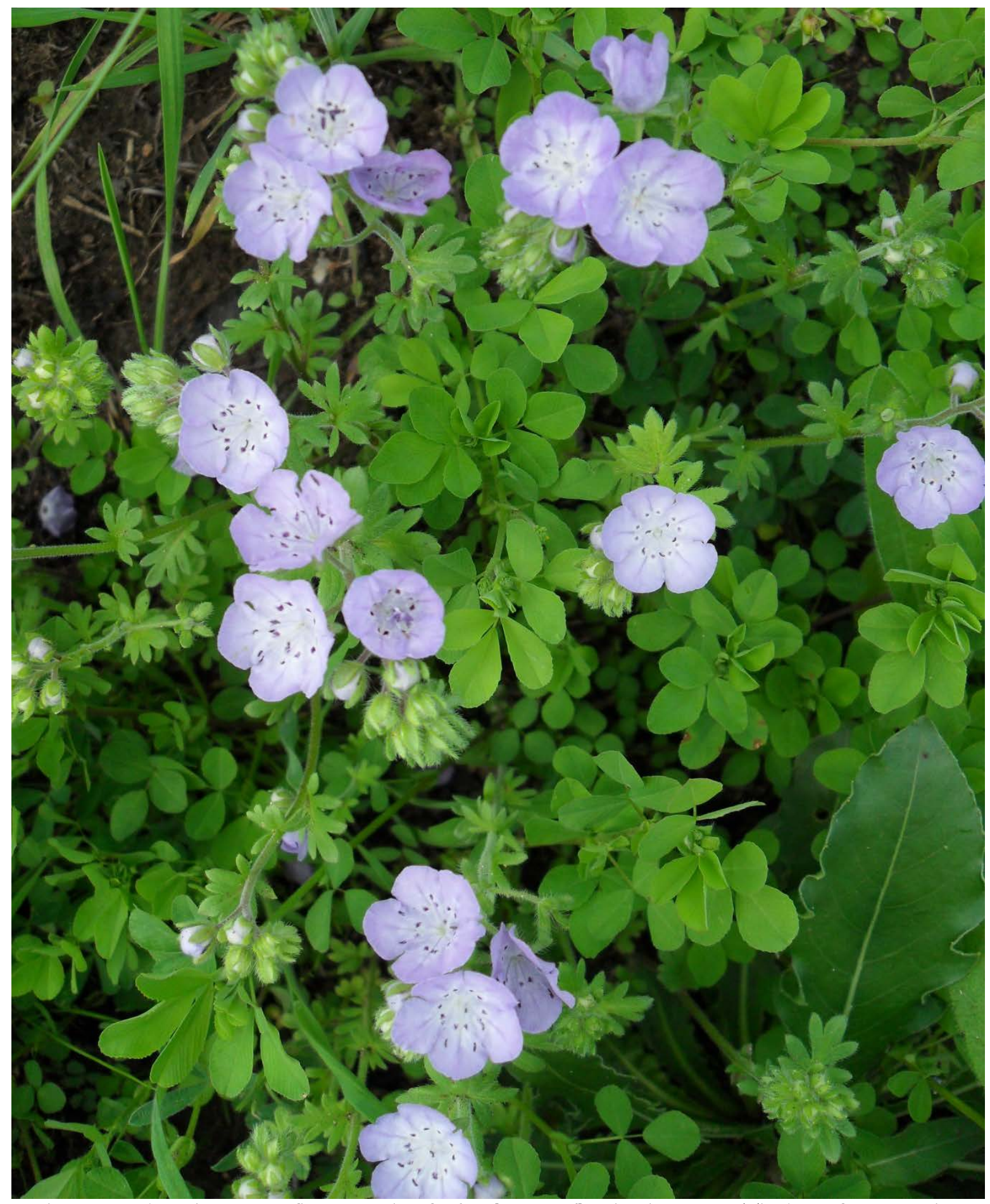

Figure 2 Abundant post-fire growth of Phacelia stricitflora in the Cross Timbers forest at the Blue River Wildlife Conservation Area in April 2012. 
We first explored the likely range of conditions that may induce germination of P. strictiflora seeds. We exposed seeds to a broad range of conditions, including: heat and smoke from a grill in which we burned dried branches of $Q$. stellata; ground ashes; physical scarification with sandpaper; a $3 \mathrm{mg} / \mathrm{ml}$ solution of Miracle-Gro ${ }^{\circledR}$ complete fertilizer; a 5\% solution of Colgin brand Liquid Smoke ${ }^{\mathbb{B}}$; sulfuric acid (diluted to $\mathrm{pH}$ $=3$ ); and ammonium hydroxide (diluted to $\mathrm{pH}=10)$. We used 30 petri plates, each with 20 seeds, for a total of 600 seeds. We kept all petri plates on racks underneath fluorescent lights in a temperaturecontrolled laboratory for a month.

For the two main experiments, we produced an aqueous suspension of smoke molecules in the following manner. We placed $150 \mathrm{ml}(5.07 \mathrm{oz})$ of water in the reservoir of a commercial hookah pipe and burned post oak wood in the bowl. We drew smoke through the water using a nasal aspirator for three hours, during which time we replenished the oak wood as it burned. The result was a water suspension that was visibly amber and smelled like smoke. We diluted some of this suspension to halfstrength, and some of it to quarter-strength. We kept the three dilutions in refrigerated test tubes sealed with parafilm to discourage the diffusion of volatile smoke chemicals and performed the experiments during storage of the water suspension.

In the first of these experiments, we compared stratified with unstratified seeds. We stratified some seeds by keeping them for a month in a refrigerator in moist paper towels inside of open plastic bags. For each of the following conditions, we then prepared four petri plates, each with 25 stratified seeds kept under the following conditions:

- Distilled water (control)

- Quarter-strength smoke solution

- Half-strength smoke solution

- Full strength smoke solution
We did the same with petri dishes of unstratified seeds. The result was a sample of 400 stratified seeds (in sixteen plates) and 400 unstratified seeds (in sixteen plates), for a total sample size of 800 seeds. We kept all petri plates on racks underneath fluorescent lights in a temperature-controlled laboratory for a month. As needed, we added distilled water to the plates, but no additional smoke solution.

In the second of these experiments, we used only unstratified seeds that had been stored in a refrigerator. We placed two control plates, two quarter-strength plates, two half-strength plates, and two full strength plates, each with 25 seeds, under the fluorescent lights $(n=200)$ and in darkness (a drawer adjacent to the lights; $n=200$ ), for a total sample size of 400 seeds. Temperature under the lights was slightly higher $\left(26^{\circ} \mathrm{C}, 78.8^{\circ} \mathrm{F}\right)$ than temperature in darkness $\left(22^{\circ} \mathrm{C}, 71.6^{\circ} \mathrm{F}\right)$.

We analyzed the germination results using a chi-square analysis. We could not use a parametric test because in many of the petri dishes no seeds germinated. The preponderance of zeroes made parametric analysis invalid.

\section{RESULTS}

None of the 600 seeds germinated in the initial studies. From this we concluded that seed dormancy in Phacelia strictiflora prevented germination in response to a flush of nutrients or a change in $\mathrm{pH}$. We also concluded that dormancy of $P$. strictiflora seeds could not be easily broken by heat or physical abrasion.

In the experiment that compared stratified with unstratified seeds, no control seeds germinated, and only one seed germinated when exposed to full-strength smoke suspension. The greatest germination occurred in half-strength and quarterstrength smoke suspension (Table 1). This pattern was significant for both stratified 
$(p=0.001)$ and unstratified $(p=0.001)$ seeds, analyzed separately. Not only did stratified seeds display lower total germination than unstratified seeds, but they germinated more slowly. Unstratified seeds began to germinate after 7 days, while stratified seeds did not begin to germinate until 21 days.

Contrasting with the preliminary experiments, the experiment that compared seeds exposed to light and darkness resulted in 11 of the 50 dark control seeds germinating. However, no seeds germinated in full-strength smoke suspension, and the greatest germination still occurred in halfstrength and quarter-strength smoke suspensions, as in Experiment $1(\mathrm{p}=0.001)$ (Table 2). Overall germination was greater in darkness than in light $(p=0.001)$

Table 1 Number and percentage of stratified and unstratified Phacelia strictiflora seeds that germinated. Each treatment contained 100 seeds $(n=800)$.

\section{Unstratified seeds Cold-stratified seeds}

$\begin{array}{lll}\text { Full-strength smoke suspension } & 0(0 \%) & 1(1 \%) \\ \text { Half-strength smoke suspension } & 54(54 \%) & 16(16 \%) \\ \text { Quarter-strength smoke suspension } & 37(37 \%) & 5(5 \%) \\ \text { Control } & 0(0 \%) & 0(0 \%)\end{array}$

Table 2 Number and percentage of Phacelia strictiflora seeds that germinated in the light and the dark. Each treatment contained 50 seeds $(n=400)$.

$$
\text { Light Dark }
$$

$\begin{array}{lll}\text { Full-strength smoke suspension } & 0(0 \%) & 0(0 \%) \\ \text { Half-strength smoke suspension } & 13(26 \%) & 21(42 \%) \\ \text { Quarter-strength smoke suspension } & 13(26 \%) & 27(54 \%) \\ \text { Control } & 0(0 \%) & 11(22 \%)\end{array}$

\section{DISCUSSION AND CONCLUSIONS}

Very few control seeds of Phacelia strictiflora germinated. We cannot explain why 11 control seeds germinated in darkness in the final experiment, while no control seeds germinated in previous experiments. One possibility is that smoke chemicals diffused through the air from plates with smoke suspensions into some control plates, since all the plates were in the same drawer. But we have observed that a few Phacelia seedlings germinate in the field in years without fire. Even the post-fire herbaceous plants of the chaparral have a low level of seed germination under control conditions; a few control seeds germinated in seven of twelve chaparral species (including $P$. grandiflora) investigated by Keeley and Fotheringam (1998a). We have nevertheless demonstrated a strong smoke enhancement of $P$. strictiflora seed 
germination, similar to that of post-fire species in fire-dependent ecological communities.

Half- or quarter-strength smoke suspension greatly enhanced seed germination. The failure of seeds to germinate upon exposure to the fullstrength suspension agrees with the conclusions of Drewes et al. (1995) that high concentrations of smoke chemicals can inhibit germination. The possibility that the seeds require exposure to light in order to respond to smoke (Todorović et al. 2005) was not supported in this species by our experiments. Greater germination in the dark in the final experiment may have resulted from the slightly lower temperature. Growth chambers with full temperature control were not available for this research.

We demonstrated that cold stratification was unnecessary as well as insufficient for germination. In southern Oklahoma, many annual species germinate and grow during the mild winters, and the same may be true of $P$. strictiflora. In fact, cold stratification appeared to mildly inhibit germination.

In the tallgrass prairie of North America, recurring fires destroy woody vegetation and promote the re-growth of perennial grasses and forbs. However, smoke enhances germination in only about one-third of prairie species (Jefferson et al. 2008). This may be due to the fact that most post-fire re-growth in the tallgrass prairie comes from the re-sprouting of perennials rather than the germination of seeds. Seed germination in prairies often occurs after soil disturbance by animals. The Cross Timbers forest is an ecotonal community between the eastern deciduous forest and the tallgrass prairie. However, even though its common name is "prairie phacelia," P. strictiflora appears to be more common in deciduous forest than in prairie habitats.

Butenolides such as karrikins may stimulate germination and promote seedling vigor even in species of plants, including agricultural plants, that do not require them
(Stevens et al. 2007; Ghehebriot et al. 2008; Lindon and Menges 2008; Nelson et al. 2009; Hong and Kang 2011). Unlike these species, however, smoke enhancement of $P$. strictiflora germination appears to be strong enough to effectively limit its growth to post-fire conditions. In this way, $P$. strictiflora more closely resembles the post-fire plant species of fire-dependent ecological communities than it does the other plant species of the deciduous forest.

A seed bank, produced by postfire growth after previous fires, is the only likely explanation of the massive postfire growth of P. strictiflora in 2012. Too few individuals grow without fire to permit such profuse germination without a persistent seed bank. The seed bank remains largely, but not completely, dormant until a fire occurs. Further, we have observed massive blooms of P. strictiflora only in Cross Timbers forests growing on granite substrate, but no such blooms in forests growing on limestone. The thinner soils that develop over granite may have, over time, favored the growth of P. strictiflora, allowing it to build up a seed bank in those soils. Investigation of the Phacelia seed bank is an opportunity for future research.

Smoke enhancement of seed germination has not been reported for other native Oklahoma plant species. We have observed another species, Selenia aurea (Brassicaceae), growing abundantly after the same fire that promoted the mass flowering of $P$. strictiflora, but the possibility that $S$. aurea benefits from or requires smoke for germination has not been investigated.

\section{REFERENCES}

Chiwocha, S., K. Dixon, G.R. Flematti, E.L. Ghisalberti, D.J. Merritt, D.C. Nelson, and J. Stevens. 2009. Karrikins: A new family of plant growth regulators in smoke. Plant Science 177 (4):252-256. 
DeLange, J.H. and C. Boucher. 1990. Autecological studies on Audouinia capitata (Bruniaceae). I. Plant-derived smoke as a seed germination cue. South African Journal of Botany 56 (6):700-703.

Dixon, K.W., S. Roche, and J.S. Pate. 1995. The promotive effect of smoke derived from burnt native vegetation on seed germination of Western Australian plants. Oecologia 101 (2):185-192.

Dixon, K., D. Merritt, G. Flematti, and E. Ghisalberti. 2009. Karrikinolide: A phytoreactive compound derived from smoke with applications in horticulture, ecological restoration, and agriculture. Acta Horticulturae 813:155-170.

Drewes, F.E., M.T. Smith, and J. van Staden. 1995. The effect of a plantderived smoke extract on the germination of light-sensitive lettuce seed. Plant Growth Regulation 16:205-209.

Flematti, Gavin R. et al. 2004. A compound from smoke that promotes seed germination. Science 305:977.

Ghehebriot, H.M. et al. 2008. Smoke-water and a smoke-isolated butenolide improve germination and seedling vigour of Eragrostis tef (Zucc.) Trotter under high temperature and low osmotic potential. Journal of Agronomy and Crop Science 194:270-277.

Hong, E. and H. Kang. 2011. Effect of smoke and aspirin stimuli on the germination and growth of alfalfa and broccoli. Electronic Journal of Environmental, Agricultural, and Food Chemistry 10 (2):1918-1926.

Jefferson, L.V., M. Pennacchio, K. Havens, B. Forsberg, D. Sollenberger, and J. Ault. 2008. Ex situ germination responses of midestern USA prairie species to plant-derived smoke. American Midland Naturalist 159 (1):251-256.

Keeley, J.E. and C.J. Fotheringham. 1998a. Smoke-induced seed germination in California chaparral. Ecology 79 (7):23202336.
Keeley, J.E. and C.J. Fotheringham. 1998b. Mechanism of smoke-induced seed germination in a post-fire chaparral annual. Journal of Ecology 86 (1):27-36.

Keeley, J.E., C.J. Fotheringham, and P.W. Rundel. 2012. Postfire chaparral regeneration under Mediterranean and non-Mediterranean climates. Madroño 59 (3):109-127.

Lindon, H.L. and E. Menges. 2008. Effects of smoke on seed germination of twenty species of fire-prone habitats in Florida. Castanea 73 (2):106-110.

Nelson, D.C., J.A. Riseborough, G.R. Flematti, J. Stevens, E.L. Ghisalberti, K.W. Dixon, and S.M. Smith. 2009. Karrikins discovered in smoke trigger Arabidopsis seed germination by a mechanism requiring gibberellic acid synthesis and light. Plant Physiology 149:863-873.

Stevens, J.C., D.J. Merritt, G.R. Flematti, E.L. Ghisalberti, and K.W. Dixon. 2007. Seed germination of agricultural weeds is promoted by the butenolide 3-methyl2H-furo[2,3-c]pyran-2-one under laboratory and field conditions. Plant Soil 298:113-124.

Thomas, P.B., E.C. Morris, and T.D. Auld. 2007. Response surfaces for the combined effects of heat shock and smoke on germination of 16 species forming soil seed banks in south-east Australia. Austral Ecology 32:605-616. Todorović, S., Z. Giba, S. Zivković, D. Grubišić, and R. Konjević. 2005. Stimulation of empress tree seed germination by liquid smoke. Plant Growth Regulation 47 (2-3):141-148.

Turner, S.R., D.J. Merritt, M.S. Renton, and K.W. Dixon. 2009. Seed moisture content affects afterripening and smoke responsiveness in three sympatric Australian native species from fireprone environments. Austral Ecology 34:866-877. 